\title{
Tropical travel and life-threatening disease: Preventing malaria misadventures
}

\author{
Anne E McCarthy MD FRCPC DTM\&H
}

$\mathrm{T}$ he recent emergence of severe acute respiratory syndrome (SARS) is a poignant reminder of our vulnerability to illness originating continents away (1). Canada is an active participant in the global village due to the migration of people and food across multiple borders. This is facilitated by modern transport, which provides the ability to circumnavigate the globe in less than $48 \mathrm{~h}$. At times, these modes of transport can act as vessels to transport pathogens across the miles (2).

Fortunately, few globetrotting Canadians will ever experience a life-threatening illness. However, with one million Canadians visiting tropical countries, an annual influx of 250,000 refugees and immigrants, and the increasing tourist traffic from distant lands, there is an expanding need for Canadian health care providers, particularly infectious disease specialists, to consider travel-related and tropical diseases in the differential diagnosis of many common health complaints $(3,4)$. Just as we incorporated routine questions about HIV risk factors into our functional inquiries in the late 1980s, it is past time to pose the question routinely "Have you travelled lately?" when evaluating any patient with fever or flu-like illness. Failure to consider malaria in the febrile patient who has visited a malaria-endemic area may mean the difference between life and death.

The good news is that most travel-related illnesses and injuries can be prevented or at least anticipated $(5,6)$. Fatalities in Canadian travellers remain uncommon and are usually cardiac-related or due to trauma, particularly motor vehicle (eg, motorcycle) mishaps (7). Deaths from infectious diseases account for less than $1 \%$ of all travel-related deaths. Yet, over the past decade, North American travellers have experienced morbidity and occasional mortality from ailments such as yellow fever (8), malaria (9-11), and dengue $(3,4)$, to name but a few. As well, immigrants to Canada, even many years after migration, can experience the consequences of pathogens acquired in their youth such as tuberculosis, strongyloidiasis, echinococcosis and neurocysticercosis (12).

Worldwide, malaria is an important cause of morbidity and mortality. It is also the most important life-threatening infectious disease faced by travellers. In Canada there are 400 to 1000 malaria cases and often one to two deaths reported annually $(9,10,13-15)$. Most malaria deaths can be prevented with early diagnosis and appropriate treatment. What is needed is immediately contemplating the diagnosis, obtaining stat thick and thin blood film results, and reacting appropriately to this medical emergency. It is sobering that many cases of severe malaria are associated with delays in therapy because the diagnosis is not seriously contemplated by the patient, or with delays in therapy at the time of their first contact with the health care system.

Over the past two years there have been 24 Canadians who required parenteral quinine therapy for the treatment of Plasmodium falciparum malaria. In 21 of these individuals, the therapy was needed because of severe or complicated disease (16). All these individuals travelled to areas that are well recognized for chloroquine-resistant $P$ falciparum malaria and none received appropriate malaria chemoprophylaxis. As well, 17 patients waited at least $48 \mathrm{~h}$ before seeking medical care for their illness. There is little doubt that this delay contributed to the severity of their illness. Appropriate pretravel advice should have ensured effective chemoprophylaxis and counsel on seeking immediate medical attention in the event of a fever or flu-like illness.

Uncomplicated $P$ falciparum infection is associated with a $1 \%$ case fatality rate, which increases 20 -fold with progression to severe disease (for example parasitemia of $5 \%$ or evidence of organ dysfunction), even when cared for in a modern intensive care unit! Progression from mild symptoms to complicated disease and even death can occur over as little as 24 to $48 \mathrm{~h}$. As an example, two recent deaths in Canada occurred within days of return from areas of known risk for $P$ falciparum. Both deaths were associated with missed diagnosis, and neither individual received appropriate therapy for their life-threatening disease. Infectious disease physicians are often on the front line (or on the phone line) assessing febrile travellers, obviously the first issue is recognizing that travel has occurred!

Once faced with the diagnosis of malaria, immediate, effective therapy is required. Guidance for the treatment of this lifethreatening infection is readily available, including Canadian recommendations by the Committee to Advise on Travel Medicine and Travel (17). Fortunately, most individuals with $P$ falciparum malaria can be treated with oral therapy. Those with severe or complicated disease require parenteral therapy. Parenteral quinine, previously only available through Health Canada's Special Access Program, is the drug of choice for the treatment of severe and complicated malaria in Canada (17). To facilitate the acquisition of parenteral quinine, the Canadian Malaria Network (previously the Malaria Centres of Excellence) was established to pre-position parenteral quinine stocks across the country for the treatment of individuals with severe or complicated malaria. The main purpose of each of these centres is the pharmacy, which provides $24 \mathrm{~h}$ access to this life saving drug. As an additional service, on request, the designated physician for each centre can provide assistance in the management of malaria cases. These distribution centres

Tropical Medicine and International Health Clinic, Division of Infectious Disease, Ottawa Hospital General Campus

Correspondence and reprints: Dr Anne McCarthy, Tropical Medicine and International Health Clinic, Division of Infectious Disease, Ottawa

Hospital General Campus, 501 Smyth Road, Ottawa, Ontario K1H 8L6. Telephone 613-737-8184, fax 613-737-8682,

e-mailsobhi@ihis.cmh.on.ca 
also gather surveillance data for all patients treated with parenteral quinine. These surveillance data (collected at the time of diagnosis and on day 28) are an essential component of the efforts to improve malaria prevention, diagnosis and management in Canada. Years ago we relied on parenteral quinidine found on emergency room crash carts for the management of severe malaria. Quinidine, with its inherent cardiac toxicity, has long been replaced by newer antiarrhythmic drugs and is no longer readily available in Canada.

So the prevention of severe malaria relies on early diagnosis and management. The diagnosis of malaria is more likely with the knowledge of the travel history. Therefore, a travel

\section{REFERENCES}

1. Poutanen SM, Low DE, Henry B, et al. Identification of severe acute respiratory syndrome in Canada. N Engl J Med 2003; 348:1995-2005

2. Miller J, Tam T, Afif C, et al. Influenza A outbreak on a cruise ship. Can Commun Dis Rep 1998;24:9-11.

3. Bellon MM, MacLean JD. A point source dengue outbreak in Canadian tourists in Barbados. Can Commun Dis Rep 1998;24:161-4.

4. McCarthy MA, Carpenter D, Goyette M, Nguyen DT. Dengue fever in Canada. Can Commun Dis Rep 1995;21:185-7.

5. Kain KC. Travel medicine. Movement and health in the new millennium. Can Fam Physician 2000;46:13-5,20-2.

6. McCarthy AE. The pre-travel consultation: More than just shots. Can J CME 2002:63-72.

7. MacPherson DW, Guerillot F, Streiner DL, Ahmed K, Gushulak BD, Pardy G. Death and dying abroad: The Canadian experience. J Travel Med 2000;7:227-33.

8. Fatal yellow fever in a traveler returning from Amazonas, Brazil, 2002. MMWR Morbid Mortal Wkly Rep 2002;51:324-5.

9. Kain KC, MacPherson DW, Kelton T, Keystone JS, Mendelson J, MacLean JD. Malaria deaths in visitors to Canada and in Canadian travellers: A case series. CMAJ 2001;164:654-9. history should be sought with any febrile illness. Front line physicians, including those in infectious diseases, need to consider the diagnosis and ensure immediate, effective therapy to prevent adverse outcomes, including death. We do well to remember the mantra that 'Fever in a traveller within three months of returning from a malaria-endemic area is malaria until proven otherwise'. It constitutes a medical emergency and should be investigated urgently with thick and thin blood films for malaria.

Further information on the Canadian Malaria Centres can be found at www.travelhealth.gc.ca or by calling the National Coordinating Centre (613-737-8899 ext 72723).

10. Quach C, Kain K, MacPherson D, Mendelson J, MacLean J. Malaria deaths in Canadian travellers. Can Commun Dis Rep 1999;25:50-3.

11. MacLean JD, Ward BJ. The return of swamp fever: Malaria in Canadians. CMAJ 1999;160:211-2.

12. Tuberculosis among foreign-born in Canada. Can Commun Dis Rep 2003;29:10-6.

13. Sharma S, Humar A, Kain KC, Zoutman D. Fatal falciparum malaria in Canadian travellers. Can Commun Dis Rep 1996;22:165-8.

14. Malaria. Deaths from malaria acquired in Africa. Wkly Epidemiol Rec 1990;65:88-90.

15. Humar A, Sharma S, Zoutman D, Kain KC. Fatal falciparum malaria in Canadian travellers. CMAJ 1997;156:1165-7.

16. Charlebois B, McCarthy AE. Cases of severe falciparum malaria in Canada: 2000-2002. Am J Trop Med Hyg 2002;67(Suppl 2):219. [Abst]. 51st Meeting of American Society of Tropical Medicine and Hygiene, November 10-14, 2002, Denver, Colorada, USA.

17. Canadian recommendations for the prevention and treatment of malaria among international travellers. Committee to Advise on Tropical Medicine and Travel (CATMAT), Laboratory for Disease Control. Can Commun Dis Rep 2000;26(Suppl 2):i-vi, 1-42. 


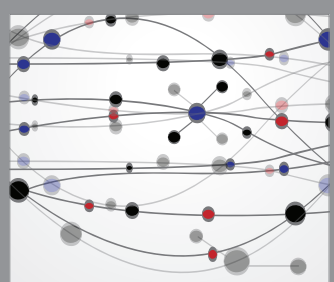

The Scientific World Journal
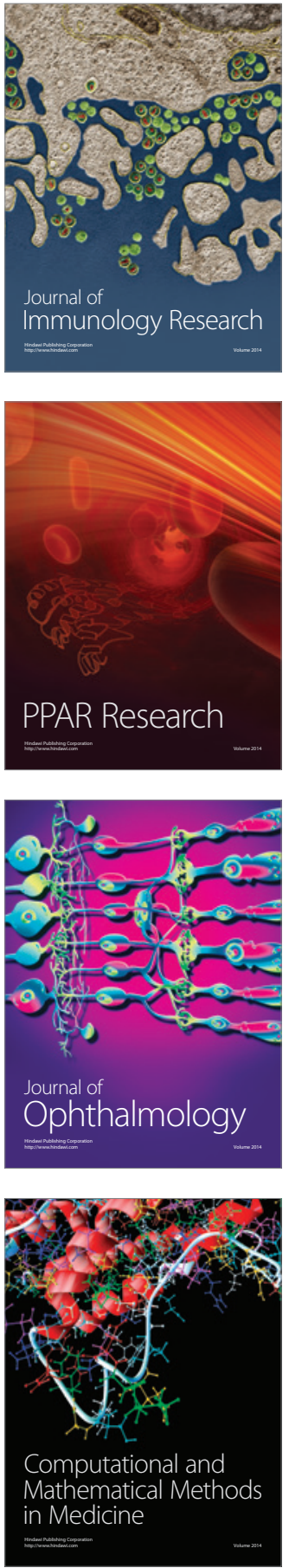

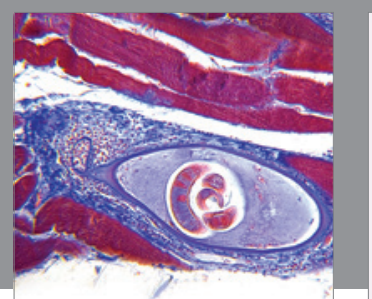

Gastroenterology Research and Practice

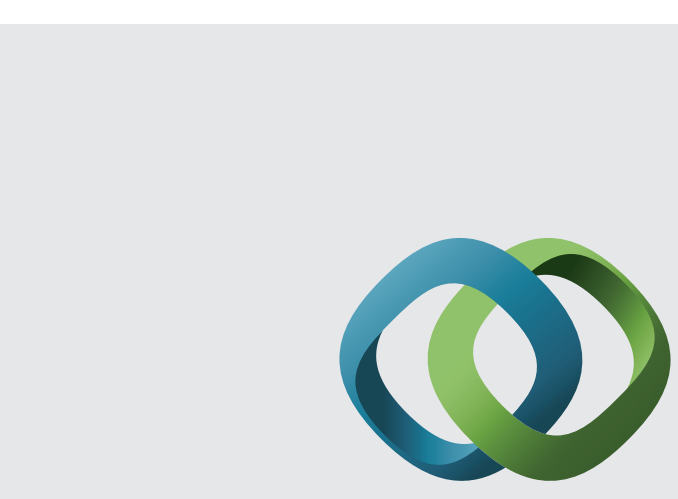

\section{Hindawi}

Submit your manuscripts at

http://www.hindawi.com
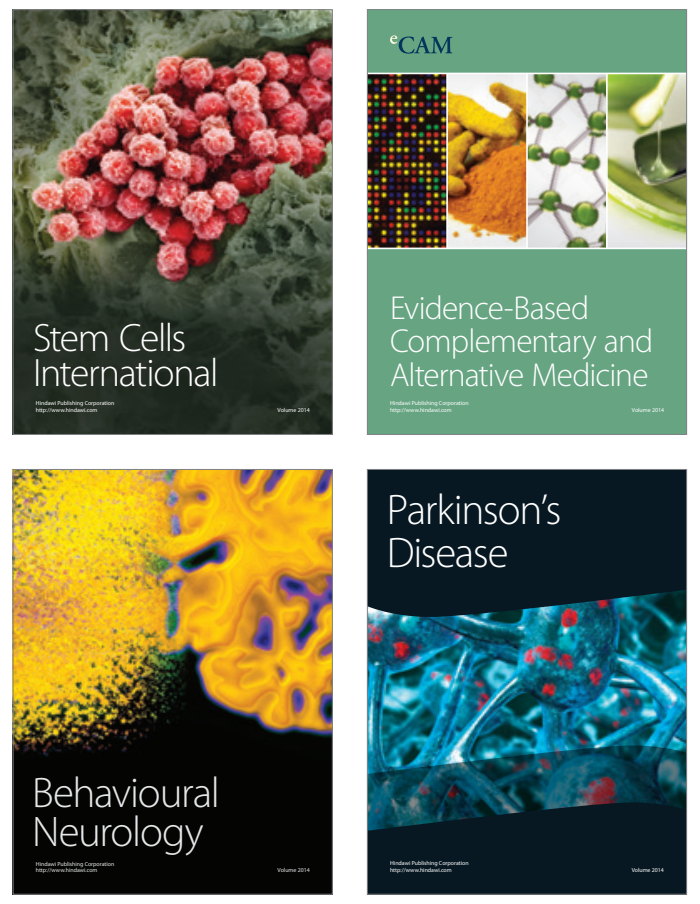
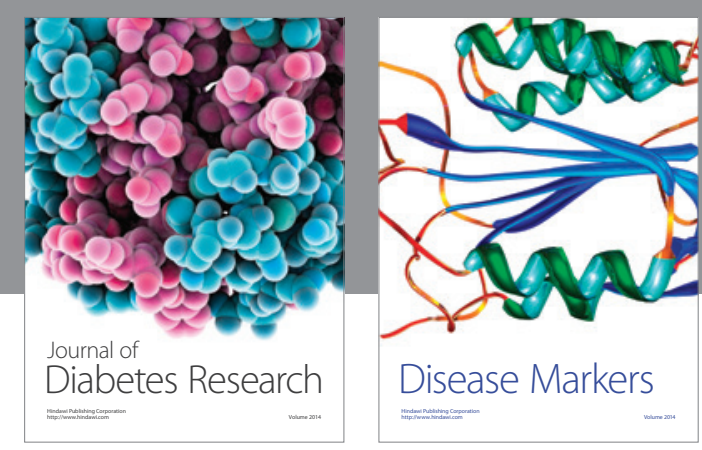

Disease Markers
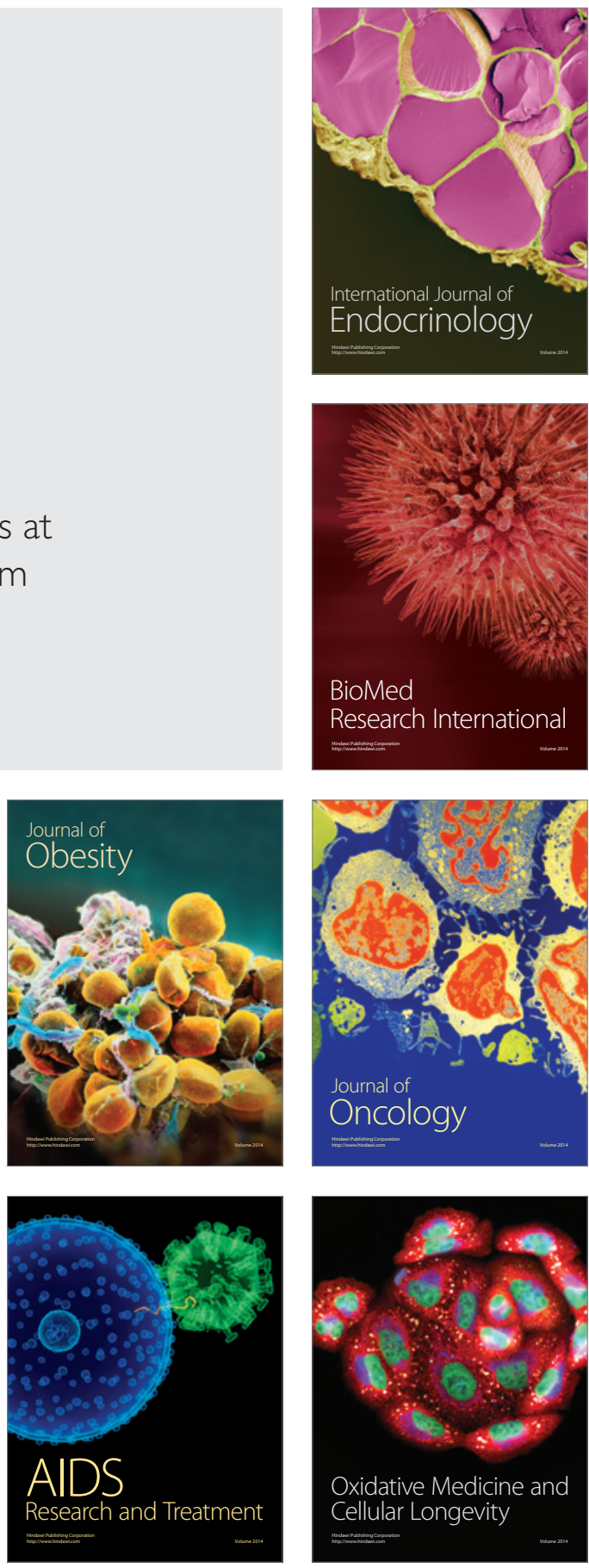